\section{Religious divisions}

SIR - In any discussion of religion, the following argument seems to me to be incontrovertible. There are many religions in the world, with several of them (including almost all branches of Christianity and of Islam) claiming to be valid for all people at all times. Each has numerous adherents of the highest integrity and intelligence. These faiths contradict each other, and so at most only one of them can be right. Accordingly a huge number of believers must be wrong. Thus it is plain that the human mind is singularly liable to be mistaken on religious issues, whatever the depth of conviction, intelligence and integrity of the faithful.

The past as well as the present can leave no doubt that the variety of religions is a calamitously divisive force in human affairs. The less this factor is brought in, the better for all. This is especially incumbent on those working in a universal and global enterprise as science is.

To come to some specific issues, there are those who claim that Christianity provided the necessary background for science with its belief in an ordered universe. How do they account for the fact that for three-quarters of the Christian era the home of science was confined to the non-Christian parts of the world, such as China, India and the Islamic countries?

It is also sometimes claimed that Christianity differs from some earlier religions by its opposition to human sacrifice. How can that be claimed for a religion that for centuries gloried in the burning of heretics and of witches?

\section{Hermann Bondi}

Churchill College,

Cambridge CB3 ODS, UK

SIR - Ralph Estling (Nature 364, 754; 1993) thinks it was unfair of me to criticize Brian Josephson's "concept of religion as an attempt to maximize human goodness" by pointing to the religion of the Aztecs and Carthaginians. I did this to avoid reference to current religions of the world but this has led to misunderstanding.

The major religions of the world are a product of social evolution and are constantly changing their character and spawning new sects. Some are fanatical enough to practise terrorism as a method of imposing their will on their enemies. The attempt to blow up the World Trade Center in New York by followers of Sheik Abdel Rahman is just one example.

Christianity, which may appear benign to a myopic, insular observer, has itself gone through phases where it dealt harshly and inhumanely with dissenters. The Inquisition, active between the fifteenth and eighteenth centuries, used methods later identified with Stalin's purges of his opponents in the 1930s. Thousands of heretics and witches were burnt alive before the conclusion of this phase of church history. There is no guarantee that it won't happen again, as the fighting in Bosnia-Herzegovina shows.

The so-called 'ethnic' cleansing of Bosnia by the Serbs is a misnomer for an attempt by Greek Orthodox Christians to eliminate the Muslims in their midst through expulsion, murder and rape. It has nothing to do with ethnicity, for both sides speak the same language and differ only in their religion. It is more brutal than the expulsion of Jews from Spain by the Inquisition at the end of the fifteenth century, yet the supposedly Christian European states stand by, unmoved by any "human goodness" that their religion may have instilled in them.

John L. Martin (in the same issue) evidently believes, along with Josephson, that any religions not conforming to the "human goodness" criterion are pathological variants, not to be included in a discussion of religion. Let me remind him that in a set of observations in physics it is not permissible to eliminate any data from a dataset unless observational errors are proved to be present. To use an arbitrary criterion for determining which data are to be included in a dataset would be simply bad physics. Logically this is equivalent to discarding all observations that show insects to have six legs because Aristotle said they have four. What I have described, colourful or not, does not fall into the category of observational errors and must be dealt with in any rational discussion of religion.

\section{Arno Arrak}

5 Chatham Place,

Dix Hills, New York 11746, USA

SIR - Michael Houlder's letter (Nature 363, 389; 1993) about Josephson's defence of a scientific analysis of religion was thoughtful and erudite. Religious beliefs are rationalizations for various behaviours. Customs and cultures are much the same and generally support the community in preference to the individual.

Humanity has, as one of its unique features, a (relatively) prolonged period of nurturing before a child matures to the adult stage. The child, in self-defence against siblings who demand the attention of parents (resources), is egocentric. Greater egocentrism leads to greater acquisition of resources and hence survival. This works up to a point. A world filled with egocentric adults would degenerate into anarchy, and populations would die out quickly.

Cultures (and with them, religions) developed to assist the child to evolve over a lifetime from supporting the self to supporting the community. Ideally, a balance is achieved between concern for the self and concern for others. In reality, a whole spectrum of behaviours develops, with disasters such as that at Waco at one (rare) extreme. On the whole, behaviours that allow one to procreate and nurture one's offspring to adulthood are the ones that survive.

Theology and social sciences fit well together in this context. Anything that occurs within the Universe is natural to it, hence theology and natural sciences might be related but the fit is not as good.

Michaelene P. Llewellyn

17-304 Observation Court,

Germantown, Maryland 20876, USA

\section{ICTP search}

SIR - A search committee has been formed to find a successor to Professor Abdus Salam, the founding director of the International Centre for Theoretical Physics (ICTP) in Trieste, Italy. This is a uniquely successful institute for fundamental research.

Although Italy pays 90 per cent of the costs of running the centre, it is now administered by the International Atomic Energy Agency in Vienna; from January 1994, the United Nations Educational, Scientific and Cultural Organization (UNESCO) will take over.

I write as one who has benefited from the centre to emphasize the importance of this appointment and to remark that the centre may suffer if the new director lacks leadership qualities and cannot deal with Italian and international civil servants and diplomats.

Among other things, ICTP exists to mitigate the intellectual isolation of physicists in developing countries. For this reason, the new director should be a citizen of a developing country and a physicist by training. The appointment should not be in the gift of the Italian government, nor should it be made as a result of political pressure on UNESCO.

\section{Saiful Islam}

Dusseldorferstrasse 13,

D-80804 München, Germany

\section{The reason why}

SIR - "Why should anyone care whether animals are conscious?" asks Sara Shettleworth (Nature 364 398; 1993). Er, well, one possible reason does come to mind. If it were widely believed that animals are "conscious", it might no longer be seen as acceptable practice to imprison and experiment on them. But of course no scientists would be influenced by considerations of that sort, would they?

\section{J. Turner}

Crystallography Department,

Birkbeck College, London WC1E 7HX, UK 